\title{
Distributional innovations of copyrighted works under conditions of sustainability
}

\author{
Martin Matušovič ${ }^{1, *}$ \\ ${ }^{1}$ University of Economics in Bratislava, Faculty of Business Management, Department of Business \\ Economy, Dolnozemská cesta 1, 85235 Bratislava, Slovak Republic
}

\begin{abstract}
Our research in the field of intellectual property has focused on selected innovative forms of distribution and protection. In examining classical innovations, we found different perspectives on their nature. Recently, we have witnessed social challenges and phenomena, which theory, practice and respondents understand as "social" innovations. The results of research into robotics, artificial intelligence, the Internet of Things and communication technologies need to be radically improved. The current epidemiological situation also significantly affects intellectual property in relation to sustainability. In terms of intellectual property records in society, our research is based primarily on generally binding internal standards, in particular our own and, in part, external resources in the field of intellectual property and innovation. Our research on boars also focused on the distribution of intangible products in pandemic conditions. We used the methodology of quantitative survey and quantitative statistical methods. Data were collected as metadata and also by direct collection. Subsequently analysed by statistical program by correlation and regression analysis. The results show that companies are aware of the importance of all kinds of innovation, intellectual property products and a significant change in distribution channels.
\end{abstract}

\section{Introduction}

The classical distribution of intellectual property has become unsustainable in pandemic conditions. In the past, we have encountered new forms of distribution of copyrighted works, intangible products using industrial property rights. Some have been less widely used in practice, others have been more popular and convenient in ways that allow us to distribute intellectual property anywhere, anytime, and all we need is internet access. The distribution of films from filmmakers to consumers through cinemas, classical theatrical

\footnotetext{
*Corresponding author: martin.matusovic@euba.sk
} 
productions and concerts must change, adapt or innovate existing forms of distribution into new ones that are in line with the needs of practice. The classic established method of production and distribution of intellectual property products is too risky in the conditions of the epidemic. [1] Innovation and creativity are becoming a crucial factor in the sustainability of economic activity. [2] Technical progress leads to innovation in the form of irregular waves of creativity. Pulses and wave intensity are based on current practice. Waves stand in the way of a new current phenomenon, although it is usually not explicitly linked to it. Our knowledge from more than a decade of research suggests that the intensity of waves in the field of intellectual property can be measured / indicated / by the extent / development / cost / investment / research. Studies performed to evaluate the task

The EU, played by innovation in the sustainability of EU small and medium-sized enterprises (SMEs), in the manufacturing sector in China ... focused on the following phenomena: to explore the types of innovation that take place in manufacturing SMEs; identify factors that have influenced innovation in the productive sustainability of SME operations; identify the link between innovation and the sustainability of SME operations. The manufacturing sector has the skills needed to carry out innovation processes as well as to design innovative practices and activities that SMEs should put into practice.

The survey was used as a research proposal. Manufacturing SMEs were grouped into sectors, layers were selected and a sample of 30 SMEs from all sectors was selected. Questionnaires and interviews were used to obtain relevant data. The collected data were presented and analysed using tables, columns, graphs of their / individually obtained and extracted from statistical packages for the social sciences. Based on the findings, innovation has been identified as one of the main attributes that help SMEs remain competitive. [3] Today we are also witnessing a test of their flexibility and creativity, as they are connected to the final player with other actors in the distribution channels. [4] The findings also point to a strong link between intellectual property innovation and the sustainability of operations. Other research findings define the characteristics of management and the ability to use and protect intellectual property as the most important factor that positively affects the activities of companies. [5] On the contrary, environmental factors were considered insufficient.

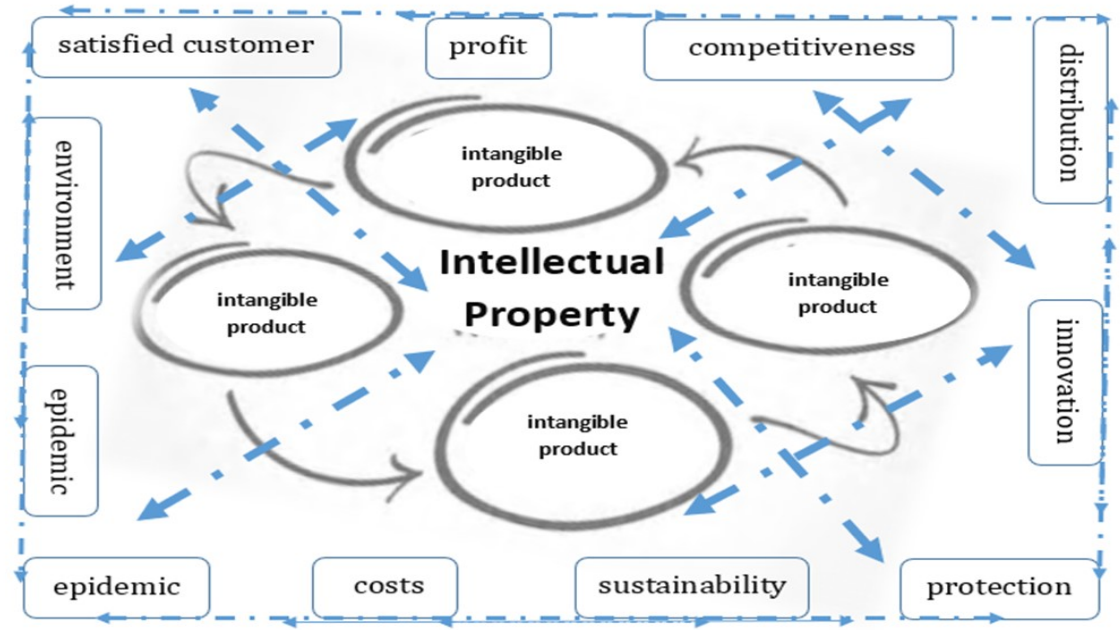

Fig 1. Selected indicators of intellectual property distribution.

Today, however, the situation is completely different. Probably research spending no longer indicates the intensity of intellectual property use. [6] This assumption can be understood as our hypothesis, which we have decided to confirm or refute our research by researche. 


\section{Present state of knowledge}

The task of distribution is to realize the transfer of goods and services from the producer to the final consumer using distribution channels. It is a set of operations ensuring the delivery of goods, services in the right quantity, quality, price and time and contributed to satisfying the needs of the consumer. The delivery process needs to be managed effectively. Distribution management is / the management of resources and processes / used to deliver the product to the point of delivery from production to the point of sale, including storage, and including wholesalers and retailers. Distribution management also involves determining the optimal amount of product for a destination. [7] Distribution management can be defined as part of order management, production, marketing, sales and finance. It brings synergies to all activities. Distribution management is the provision of the movement of goods and services through various combinations of distribution channels, transport, planning and control of warehousing / delivery /, using an information system to monitor the processing of orders. [8] Physical distribution identifies the existing situation, monitors the environment, identifies potential opportunities and threats. Some manufacturers are also distributors. However, most manufacturers do not supply their products directly to the final consumer and use the services of intermediaries / distribution intermediaries, distribution assistants. Wholesalers, retailers, publishers and other entities together form a distribution channel. The decision to choose a distribution channel depends on various factors. Depending on the nature of the product and processes, intermediaries perform different roles in the distribution process. [8] The Typology of Distribution Channels can be derived from this. Direct distribution channel / manufacturer distribution itself directly to the consumer. Performs all distribution activities at its own expense and risk. In the case of copyrighted works, this situation depends on the product. [9] The indirect distribution channel / the manufacturer involves one or more entities in the realization of his products /. In part or in full, these entities assume production and distribution activities / costs, risk, and often participation in copyright with the exception of personal rights. The choice of distribution channel is determined by several factors: size of the target market, specificity of the target market, product characteristics, production and distribution costs, economic potential of the author, producer, distributor consequences of the pandemic, sustainability, new technologies, movement of copyright works in digital space, author's position, new protection requirements and others.

Slovak, European and world legislation regulates the rights of the entities involved and the relations between them. Emphasis is placed on: a high level of protection, settlement of rights, creation of a framework for the use of the work, other objects of protection, stimulation of innovation, creativity, investment, production, distribution, including in the digital environment, new business models, new entities, access to content, access to research, innovation, education and heritage conservation. Consideration is given to introducing / extending / mandatory and optional exemptions for the use of text and data mining technologies, for teaching purposes and for the preservation of cultural heritage in the digital environment. Existing exceptions and limitations in Union law should continue to apply as long as they do not limit the scope of the mandatory exceptions. Exceptions and limitations are intended to ensure a fair balance between the rights and interests of authors and other rightholders on the one hand and users on the other. They may be applied only in cases where they do not conflict with the normal use of the works and do not unreasonably prejudice the legitimate interests of rightholders.

The copyright law of each country regulates the producer of an audiovisual work, resp. the person who started or ensured his final production is considered to be the manufacturer. Unless otherwise agreed. [10] The exercise of proprietary rights depends on the authors and 
owners of the rights to the works. The original owner / author of the work / decides on the distribution of the work by exercising his personal rights. In the case of dissemination decisions, it significantly affects the distribution process. This decision is conditioned by many factors. The distributor chooses a direct or indirect distribution path. Indirect distribution is associated with the transfer of part of the property rights to third parties. The producer, seller, distributor, broadcaster of the work have partial and temporary rights to use the rights to the work in the form of licenses or sublicenses. A license may be granted for one or more uses, so the specific use of the work in the license agreement must be well defined. "The author may grant the user permission to sublicense third parties if the author agrees to the further use of the work in the license agreement. License fees for the use of the work may be agreed on a flat rate. They may also be determined as a proportion on an agreed basis. Stakeholders may also agree on a combination of these options. [11] The Copyright Act also regulates the representation of authors by a collective management organization. [12] This is the representation of authors or heirs and other owners in certain copyrights. The indirect form of distribution can be associated with a complex system of entities and relationships. The involvement of new digital / intelligent / works distribution platforms causes this system to be more complex and opaque. [13]

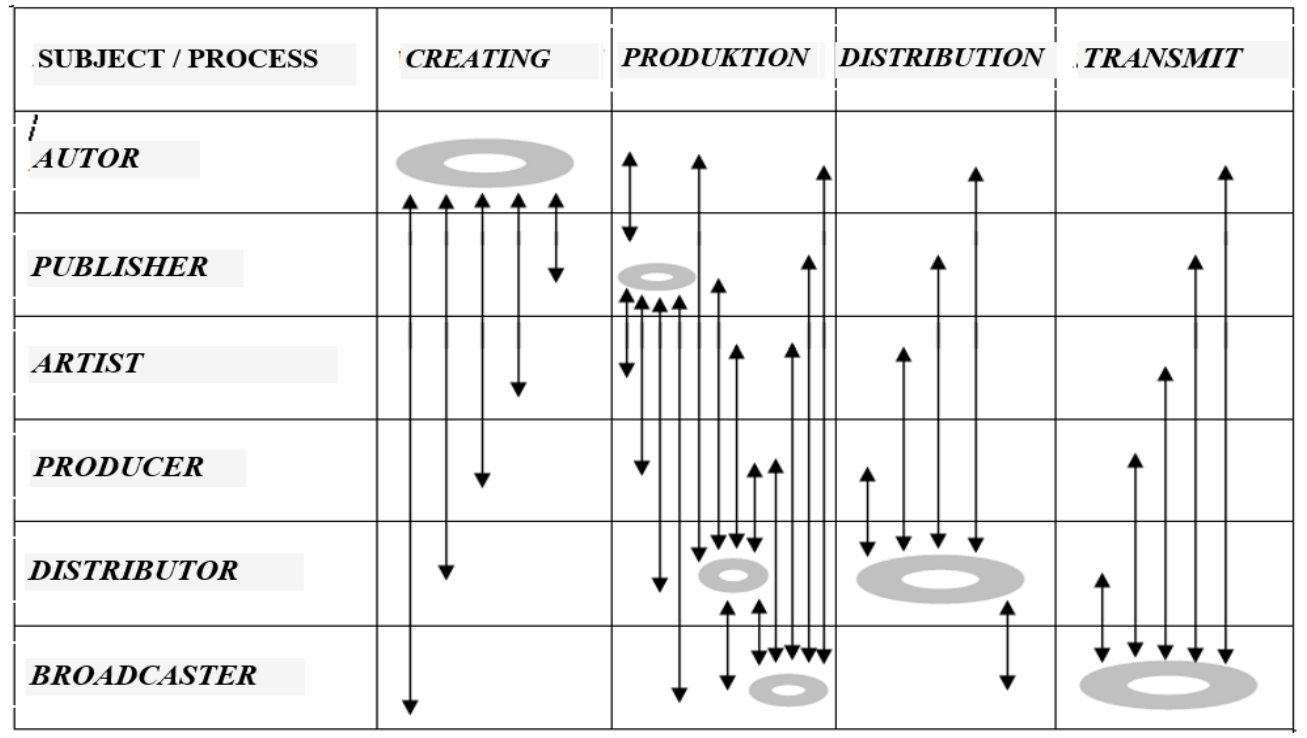

Fig 2. Selected subjects and process of intellectual property distribution.

Direct distribution of works is possible today mainly due to the rapid development of various technological platforms. However, the use of these platforms is associated with several pitfalls in securing distribution channels and new ways of licensing the provision of property rights to third parties. [14]

\section{Methodology and research design}


We used recognized general scientific methods in our research. We obtained information from existing literature. We also used empirical methods / observation, structured interviews /. We also examined existing metadata. When examining the data, a system approach / methodology of examining the spread of phenomena was applied without disturbing the overall context and links. We used other general methods of scientific research / analysis, synthesis /. The analysis was used to determine the bonds between the parts of the whole. The synthesis allowed us to formulate the conclusions of the research. We researched the content of selected concepts, current knowledge, models, selected processes in the real practice of sustainable distribution of copyrighted works. In the context of the most comprehensive review of the current state of innovation. We have defined selected indicators and problems of distribution process management in all phases of the life cycle. We focused our research goals on innovation and sustainable distribution of works: - we assume that in terms of innovation there is an ambiguous understanding and use of selected terms in terms of content, literature on the content of social innovation is inconsistent - we assume that more than half of respondents think they do not know or they do not know exactly what social innovation is. We assume that the distribution of works needs to be modified procedures. The formulated research goals were met by standard methodological steps. We also did our own research. We selected suitable research tools and methods, we identified a specific target object and subjects. We created our own database and processed the data and translated it into measures. The research used the method of purposeful analysis (questionnaire survey), which was focused on a selected sample. In the questionnaire, we formulated several questions in order to obtain evidence to achieve research goals. The questions were formulated in order to characterize the respondents, to characterize the individual subjects of the survey and to state the real state of innovations in the business sphere. First, we tried to look for data that someone in front of us had collected and analyzed. We had to supplement the existing data. For these reasons, we have collected our own data. We also examined the preferences of Slovak viewers for various forms of distribution of copyrighted works. A total of up to 100 respondents aged 15 and over participated in the survey; the upper age limit was not limited, more than half of the respondents were women and the remaining were men with different education. The questionnaire was distributed electronically and contained closed questions. Given the number of respondents involved, this is not a representative sample. The data obtained can at least partially serve to create an idea of the preferences and attitudes of the final consumer in the field of sustainability of the distribution of works.

\section{Research results}

We evaluated 250 opinions of respondents, mostly limited liability companies and sole traders. More than two thirds of companies are based in the Bratislava region with an average age of 15 years. The main activity of companies is mainly focused on services. We processed the collected data and gradually analyzed them. For some questions, respondents were offered possible answers, while others were asked to add specific information or express the respondent's opinion. Correspondents are relatively young people of working age. Externally cooperating respondents make up 18\%. A small proportion of respondents also work as an accountant or economist. The structure of respondents is dominated by men aged approximately 35 years. Mostly these are the positions of owner, manager and manager. We briefly characterize the analyzed companies, the structure of legal forms, capital, including the extent of foreign participation, registered office, age, main activity, industry structure and size. We characterized the sample in more detail and took all the facts into account in the analysis and conclusions. The questions asked offer a choice of one 
or more legal forms of the business offered and at the same time provided respondents with the opportunity to add another institution dealing with intellectual property. When formulating the question, we assumed that the respondents would add other institutions, not just companies. It also happened in the range of $7 \%$. However, respondents did not provide details of the institutions involved. We would also like to emphasize that $1 \%$ of respondents answered the questions asked in the questionnaire as a private person. Respondents' answers to equity documented more than half the dominance of domestic capital alone. Less than half of respondents declared a share of foreign capital of over $51 \%$. We were also interested in the development of innovative activities. An increase in innovation activity was recorded in Bulgaria, Denmark, ahead of the Netherlands, Estonia, Ireland, Latvia, Lithuania, Belgium and the USA. The Slovak Republic and the Czech Republic recorded an increase in innovation activity at the same average level within Europe. Innovation activity was below the EU average was Finland, Germany, Luxembourg, Austria, France and Italy. The decline in activity was in several countries: Portugal, Malta, Greece. The most successful innovators grew by an average of $0.15 \%$. The group of less successful innovators recorded an average decrease in innovation activity of $1.8 \%$. The weakest group of innovators fell by $4.3 \%$. Slovakia was a medium innovator. in 2010 and 2013 it also decreased. The performance of the Slovak Republic in relation to the EU has larger fluctuations. The EU peaked in 2012 (to $69 \%$ of the EU average), but also fell in 2014 (to $64 \%$ of the EU average). Slovakia maintained its position below the EU average in all monitored indicators. Recent findings at European level from 2019 show that innovation performance has been steadily improving in recent years. Europe has performed better in terms of innovation than the United States. Sweden performed best in terms of innovation, followed by Finland, Denmark and the Netherlands. The United Kingdom and Luxembourg have fallen from the top group of innovation leaders to strong innovators. Europe's innovation has improved in most indicators. The increase in indicators recorded for trademarks, patent applications, licensing, expenditure on research, development, innovation and others contributed significantly to the success. Despite the fact that the Slovak Republic experienced a shift in the period under review, its position within the Community did not improve much. It is still below the EU average. It is clear that the methodology for calculating the innovation of countries will not withstand frequent corrections. It would certainly be to the detriment of the comparability of historical data. In our view, it is possible to object to global comparability even now. Surprisingly, it is difficult to correctly examine and compare the state of intellectual property and its impact on the innovation of companies, employees and especially individuals. With certain reservations and commitment, it is possible to design and test a model involving industrial property. From our point of view, such an analysis in relation to the works of the authors is not feasible. Substantial innovations / especially in the field of technology / in relation to works are actually taking place in the environment. These innovations and related changes generate significant challenges for copyright entities and relationships. So far, we have not noticed any steps by the regulator in this area. New phenomena, subjects and relationships are emerging. The position of authors in securing their rights is constantly deteriorating. This situation is unsustainable in the future. 


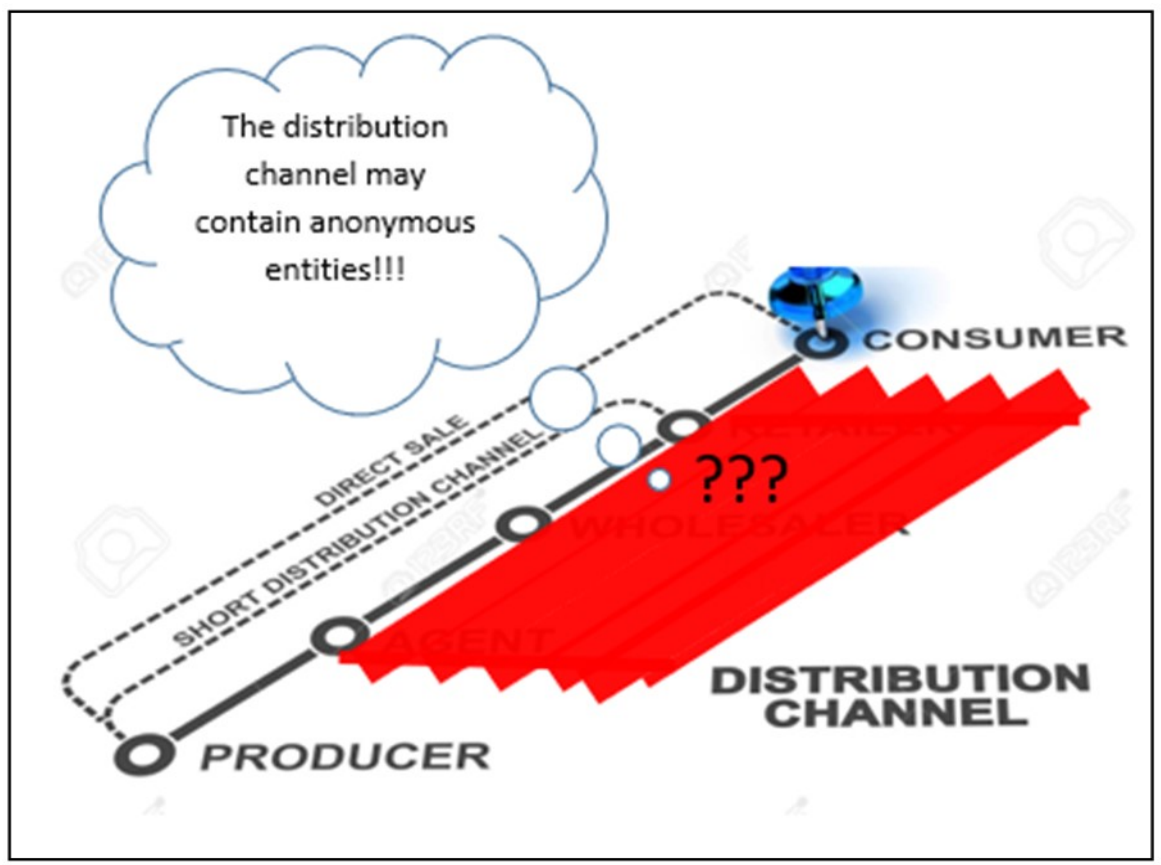

Fig 3. Distribution channel of intellectual property in internet.

\section{Summary}

Almost three quarters of respondents think that they do not know exactly how to define the essence of all kinds of innovation. Experts believe on the nature of social innovation. Some speak of a clear definition, others question the definition. Intellectual property research is based on legislation. The potential of intellectual property is not always the property of the company. Part of the rights / especially personal / are non-transferable. Therefore, the author, the originator is not always directly connected with the company and we only partially record intangible assets. leased, Externally purchased intangible products are problematic to keep track of records. Inaccurate data were obtained from the respondents' own survey. The questions were to refine the existing real data to achieve the research goal. We do not consider the obtained data set to be statistically significant, which may affect the reality of the results. The average value of the scope of research activities is $\mathrm{M}=7,492$; standard deviation $\mathrm{SD}=10.9$. Minimum value $\mathrm{Min}=0$, $\operatorname{maximum} \mathrm{Max}=50$. The result of the research confirmed the inconsistency of records with reality. We also examined the correlation of selected parameters in order to identify the right indicators to measure the effects of the research results. We found a correlation between research spending, employment, turnover, wages and bonuses. The current situation has affected practically the whole world. Innovation has necessarily focused on digital technologies. They are being radically promoted in all areas of business and life. They have caused radical innovations in relation to the distribution of works. These innovations and related changes generate significant challenges for copyright entities and relationships. So far, we have not noticed any steps by the regulator in this area. New phenomena, subjects and relationships are emerging. The position of authors in securing their rights is constantly deteriorating. This situation is unsustainable in the future. 
The paper is an output of the science project VEGA MŠ SR no. 1/0708/20 "Socioeconomic determinants of sustainable consumption and production in terms of impact on the performance and competitiveness of enterprises"

\section{References}

1. G. Dubcová, K. Grančičová, D. Hrušovská, Customer Satisfaction and Loyaltytowards Companies in the Slovak Republic. Business Economics, Management and Marketing 2018. Proceedings of the International Scientific Conference, Brno : Masaryk University, 61-68, (2018)

2. G. R. Rughuram, L. Zingales, Saving Capitalism from the Capitalists Crow Business, 486 p., (2003)

3. M. Piko, Autorské práva nie sú zadarmo ani bez byrokracie, online at https://www.podnikajte.sk/pravo-a-legislativa/c/750/category/dusevnevlastnictvo/article/autorske-prava-nie-su-zadarmo-ani-bez-byrokracie.xhtml (2012)

4. A. Jaffe, Analysis of public research, industrial, and commercial innovation, online at https://motu.nz/our-work/productivity-and-innovation/science-andinnovation-policy/analysis-of-public-research-industrial-r-and-d-and-commercialinnovation/ (2011)

5. D. Rybárová, Creative Industry as a Key Creative Component of the Slovak Economy. Globalization and its Socio-Economic Consequences 2019, Sustainability in the Global-Knowledge Economy. - Zilina : University of Zilina, Faculty of Operation and Economics Transport and Communications, (2019)

6. H. Majdúchová, B. Siváková, J. Kintler, Systematic risk determinants. International scientific conference of business economics, management and marketing. ISCOBEMM 2017. Proceedings of the [2nd] international scientific conference of business economics, management and marketing, Brno : Masaryk University, 60-170, (2019)

7. P. Kansal, S. Kapoor, Basic of Distribution Management, A Logistical Approach, 257 (2005)

8. F. Daňo, P. Kita, Distribučný manažment. Bratislava 2009, Daniel Netri. 235p., (2009)

9. H. Majdúchová, M. Kmerty Barteková. Innovations in the Creative Industry Entities, Globalization and its Socio-Economic Consequences 2019. International Scientific Conference. Sustainability in the Global-Knowledge Economy. - Zilina : University of Zilina, Faculty of Operation and Economics Transport and Communications, (2019)

10. T. Pacek, A. Mittelman, The current trends in the development of the right of intellectual property (not only) in the conditions of SR. Social Sciences and Arts SGEM 2015, Albena, Bulgaria, 715-721, (2015)

11. T. Gengyan, Analysis on the Position of Copyright Trade in the Sino-US Trade Frictio, Publishing Research Quarterly 36, 284-295, (2020)

12. B. P. Krages, Pirates and Publishers: A Social History of Copyright in Modern China, International journal of communication systems, (2020)

13. J. Kissová. Problematika marží v obchode. Aktuálne problémy podnikovej sféry 2015 Proceedings of the International Scientific Conference, Bratislava 2015, EKONÓM, 292-297, (2015)M. Matušovičová, D. Matušovič Recovery of the European Asset Management Ten Years After the Financial Crisis, Croatian Economic Association, 2019, 70, no. 5, 782-801, (2019) 
14. M. Matušovičová, D. Matušovič. Recovery of the European Asset Management Ten Years After the Financial Crisis. Croatian Economic Association, 2019, vol. 70, no. 5, pp. 782-801, (2019) 